This is the peer reviewed version of the following article: Chattopadhyay, S, George, A, John, J, Sathyapalan, T. Postload glucose spike but not fasting glucose determines prognosis after myocardial infarction in patients without known or newly diagnosed diabetes. Journal of Diabetes. 2021; 13: 191- 199, which has been published in final form at https://doi.org/10.1111/1753-0407.13111. This article may be used for non-commercial purposes in accordance with Wiley Terms and Conditions for self-archiving.

\title{
Post-load glucose spike but not fasting glucose determines prognosis after myocardial infarction in patients without known or newly diagnosed diabetes.
}

Running Title: Post-load glucose spike and post-MI prognosis

Sudipta CHATTOPADHYAY ${ }^{\text {, }}$ Anish GEORGE ${ }^{2}$, Joseph $\mathrm{JOHN}^{3}$, Thozhukat SATHYAPALAN ${ }^{4}$

Affiliations:

Department of Cardiology, Milton Keynes University Hospital, Milton Keynes, UK.

Sudipta.Chattopadhyay@nhs.net

2Department of

Cardiology, Scunthorpe General Hospital, Cliff Gardens, Scunthorpe, UK. anish26g@yahoo. com

${ }^{3}$ Department of

Cardiology, Castle Hill Hospital, Kingston upon Hull, UK. Joseph.John@nhs.net

${ }^{4}$ Department of Academic Endocrinology, Diabetes and

Metabolism, Hull York Medical School, University of Hull, Kingston upon Hull, UK.

Thozhukat.Sathyapalan@hyms.ac.uk

Corresponding author: Sudipta Chattopadhyay,

Postal Address: Department of Cardiology, Milton Keynes University Hospital, Standing

Way, Milton Keynes MK6 5LD. United Kingdom.

Phone: 004401908660033

Fax: 004401908660048

E-mail: Sudipta.Chattopadhyay@nhs.net;

\section{Abstract}

Background: Effect of post- load glucose spike (PGS), the difference between 2-hour post-load (2h-PG) and fasting plasma glucose (FPG), on post-Ml prognosis in non-diabetic patients is unexplored.

Method: Retrospective cohort analysis of 847 non-diabetic post-MI survivors who underwent pre-discharge oral glucose tolerance test (median PGS: $2.4 \mathrm{mmol} / \mathrm{l}$ ). Patients, divided into unmatched Groups 1 and 2 (PGS $\leq$ and $>2.4 \mathrm{mmol} / \mathrm{l}$ ) and propensity score matched Groups $1 \mathrm{M}$ and $2 \mathrm{M}$ (355 pairs assembled from the overall cohort) were compared. Major adverse cardiac events (MACE: death and non-fatal reinfarction) were recorded during follow up (median: 3.4 yrs). Event freesurvival was compared by Kaplan-Meier method. Multivariate Cox proportional hazard regression determined predictors of MACE. C-statistics ( $\delta A \cup C)$, continuous net reclassification improvement $\left(\mathrm{NR}^{\circ 0}\right)$ and integrated discrimination index (IDI) were used to compare models.

Results: MACE was higher in Groups $2(27.3 \% \vee 14.2 \%, \mathrm{p}<0.001)$ and $2 \mathrm{M}(24.5 \% \vee 15.5 \%$, $\mathrm{p}<0.001$ ). Event free survival was worse in Groups 2 (HR 2.01, 95\% Cl 1.49 to 2.71, $\mathrm{p}<0.001)$ and $2 \mathrm{M}(\mathrm{HR} 1.63,95 \% \mathrm{Cl} 1.17$ to $2.27, \mathrm{p}=0.004)$. PGS independently predicted MACE free survival in the whole (HR 1.16, 95\% Cl 1.06 to $1.26, p=0.002)$ and matched cohort (HR 1.12, 95\% Cl 1.02 to 1.24, $\mathrm{p}=0.021)$. PGS, but not FPG or $2 \mathrm{~h}-\mathrm{PG}$, improved the predictive performance of base model ( $\delta A \cup C 0.013, p=0.046$ ) with greater improvement seen when PGS was added compared to 2h-PG (סAUC 0.005, $p=0.034, N R 1>0.2107$, $\mathrm{p}=0.013$, IDI 0.0042, $\mathrm{p}=0.046$ ).

Conclusion: PGS is better predictor of post-MI prognosis than $2 \mathrm{~h}-\mathrm{PG}$ in non-diabetic patients. 
Highlights

1. The first study to suggest that post-load glucose spike (PGS) defined as the difference between 2 hour post-load and fasting glucose measured after $\mathrm{Ml}$ is robust enough to predict post Ml prognosis in patients without known or newly diagnosed diabetes.

2. In patients without diabetes, PGS is a stronger determinant of post-MI prognosis than 2-hour post-load glucose.

Keywords:

Diabetes mellitus, Oral glucose tolerance test, Myocardial infarction, Acute coronary syndrome, Glucose spike, Glucose excursion

\section{Background}

The adverse effect of post-load glucose on post-Ml prognosis in patients with newly diagnosed diabetes mellitus (NDM) or pre-DM (pDM) is well established. ${ }^{1-16}$ However, the effect of post- load glucose spike (PGS), defined as the difference between fasting (FPG) and 2-hour post-load plasma glucose (2h-PG), on post-MI prognosis in non-diabetic patients has not been studied. The adverse prognostic effect of PGS in non-diabetic population was suggested in the Diabetes Epidemiology: Collaborative Analysis of Diagnostic Criteria in Europe (DECODE)study ${ }^{17}$ where the number of deaths in patients increased as the difference between the fasting and $2 \mathrm{~h}-\mathrm{PG}$ increased. PGS, but not FPG or $\mathrm{HbA} 1 \mathrm{c}$, in non-diabetic subjects is positively associated with extent and progression of atherosclerosis ${ }^{18-22}$, coronary plaque and plaque vulnerability. ${ }^{23-27}$

Glycaemic variability (GV), that has been used to characterise hyperglycaemic spikes or 'excursions' especially following meals using continuous glucose monitoring (CGM) or self monitoring of blood glucose (SMBG) adversely affected post-ACS prognosis in some ${ }^{28-31}$ but not other studies. ${ }^{22-34} \mathrm{~A}$ third to two-thirds of the patients included in these studies had diabetes mellitus (DM), a group where post-ACS prognosis is already known to be worse than in those without. GV is not identical to PGS, measuring it is cumbersome; requiring specialised equipment for CGM or frequent needle pricks for SMBG and denotes relative variability in blood glucose and not the absolute magnitude of glycaemic spikes. Such monitoring can only be justified in patients with known DM or at least admission hyperglycaemia to assist clinicians in titrating therapies and where monitoring hypoglycaemia is as important as hyperglycaemia. Its use only to determine post-ACS prognosis in patients without diabetes is difficult to argue for. We undertake this study to assess whether a single measure of post-challenge glucose spike is robust enough to predict post-ACS prognosis in patients without known or newly diagnosed diabetes.

\section{Methods}

Study Population

We retrospectively analysed data on consecutive MI survivors not known to have DM discharged from our institution between November 2005 and October 2008 who underwent pre-discharge oral glucose tolerance test (OGTT), collected for the Myocardial Infarction National Audit Project. A standardised dataset that included age, gender, risk factors for coronary artery disease (CAD), past medical history including history of previous $\mathrm{Ml}$ and revascularisation, all medications, troponin I, haemodynamic status, creatinine level, presence of heart failure and ECG changeswas analysed. The Global Registry of Acute Coronary Events (GRACE) risk score (GRS) for mortality and re-infarction up to 6months post-discharge was calculated using a web-based calculator. Patients underwent routine OGTT on or after 3 days of admission. FPG was measured after $\geq 8$ hours of overnight 
fasting and $2 \mathrm{~h}$-PGwas measured 2 hours after administration of $75 \mathrm{~g}$ glucose in $200 \mathrm{ml}$ water. Patients who did not tolerate or refused OGTT and those transferred to others centres before OGTT were not considered for the study. Patients with pre-DM were advised lifestyle changes in the cardiac rehabilitation clinic and flagged up for surveillance with their family physicians.

\section{Definitions}

MI was defined according to the universal definition. ${ }^{35}$ Diabetes was labelled as "known" if the patient gave a history, it was recorded in there medical notes or was on treatment. Patients without "known diabetes" were not screened with $\mathrm{HbA} 1 \mathrm{c}$ as not recommended at the time of data collection. ${ }^{36-38}$ All the patients with NDM (FPG $\geq 7.0$ and/or 2-h PG $\geq 11.1 \mathrm{mmol} / \mathrm{l}$ ) were excluded from the analysis. The rest of the patients with NGT: FPG $<6.1 \mathrm{mmol} / \mathrm{l}$ and $2-\mathrm{h} P G$ $<7.8 \mathrm{mmol} / \mathrm{l}$, IFG: FPG 6.1-6.9 mmol/l and $2 \mathrm{~h}-\mathrm{PG}<7.8 \mathrm{mmol} / \mathrm{l}$ and IGT: FPG $<5.6 \mathrm{mmol} / \mathrm{l}$ and $2 \mathrm{~h}-\mathrm{PG} 7.8-11 \mathrm{mmol} / /$ patients were included in the study. The post-glucose spike (PGS) was defined as the difference between the $2 \mathrm{~h}-\mathrm{PG}$ and FPG. The study population was divided into two groups; Group 1: PGS $\leq$ median PGS (2.4 mmol/l) and Group 2: PGS > 2.4 $\mathrm{mmol} / \mathrm{l}$. To mitigate the differences in the baseline characteristics that are likely to affect prognosis of the patients, propensity score matching was used to assemble a paired cohort of patients in the two groups (Group1M and Group2M) with similar baseline characteristics.

\section{Follow up}

Hospital and general practice patient records were manually checked for the first occurrence of major adverse cardiovascular events (MACE) defined as death or non-fatal re-infarction, over the follow up period of 5 years (median 3.4 years). Completeness of follow up was carefully ensured by manual review of hospital and general practice records. Mortality data was verified from the general practice records linked to the national death registry. The East Yorkshire and North Lincolnshire Research Ethics Committee waived the need for formal ethical approval and patient consent as this was a retrospective analysis of routine data collected for the national audit. ${ }^{9}$

\section{Statistics}

Continuous variables are presented as medians (inter-quartile range, IQR) and categorical variables as counts and proportions. The baseline characteristics in the patients in the Groups were compared with Mann-Whitney test for continuous variables and chi-squared test for categorical variables. Kaplan-Meier method and log-rank test was used to compare the event free survival. Regression models were adjusted for covariates in the conventional fashion for the "overall" analysis for the whole cohort. Logistic regression was used to compare the incidence of MACE in the two groups. Multivariate Cox proportional hazard regression modelling was used to analyse the effect of several variables on event free survival. The base modelincluded the following co-variates: gender, smoking status, hypercholesterolaemia, hypertension, history of previous acute MI, diagnosis at discharge, discharge prescription of aspirin, clopidogrel, beta-blockers, angiotensin-converting enzyme inhibitors and statins, inpatient revascularization status and GRS for 6 months from discharge for death and MI. Variables already included in the GRS were not included separately. Hazard ratios with associated $95 \%$ confidence intervals (Cls) are reported. Any covariate with variance inflation factor (VIF) $>4$ (MedCalc Statistical Software version 17.0.4, Ostend, Belgium), were not included in the same model to avoid the effect of multicollinearity. 2h-PG and PGS (VIF 9.8 in the whole cohort) were not included in the same model.

Logistic regression models, created by adding PGS, 2h-PG and FPG individually and in combinations to the base model, were used to calculate predicted probabilities of MACE for each subject. Improvement in the predictive performance of the restricted models on addition of a covariate was examined from these predicted probabilities using different tests of improvement in discrimination: increase in the area under the receiver operating 
characteristic curve (AUC) (MedCalc Statistical Software version 17.0.4, Ostend, Belgium), category-free continuous net reclassification index $(\mathrm{cNRl}>0)$ and integrated discrimination improvement (IDI). Without pre-defined clinical risk thresholds for the models categorical NRI was not used. The event (NRle) and non-event NRI (NRIne) are the net percentage of patients with and without MACE correctly assigned a higher and lower predicted risk by the newer model with the added covariate, respectively. The overall NRI is the sum of the net proportions of individuals with and without MACE correctly assigned a different predicted risk and is reported as a number. The IDI is defined as the mean difference in predicted risks between those with and without events.

Propensity-matching was done for the matched part only. Propensity scores were computed for the whole cohort from above logistic regression models using all the covariates included in the base models except the glycaemic matrices. Bipartite matching with 1:1 ratio was performed using greedy algorithm with a fixed calliper to construct a paired cohort of patients from Group 1 and 2. The outcomes in these two matched groups were compared.

\section{Results}

Baseline characteristics

After exclusion of 206 patients with newly diagnosed DM, 847 patients were included in the study, of which 469(55.4\%) had NGT, 6 IFG, 23 IFG combined with IGT and 349 isolated IGT. PGS was 1.5 (IQR 0.8 to 2.1) in the NGT group, and 4.0 (IQR 3.3 to 5.0) in the pDM group. The median PGS for the entire cohort was $2.4 \mathrm{mmol} / \mathrm{l}(95 \% \mathrm{Cl} 2.3$ to 2.6$)$. There were 430 patients in Group 1 (PGS $\leq 2.4 \mathrm{mmol} / \mathrm{l})$ and 417 in Group 2 (PGS>2.4

$\mathrm{mmol} / \mathrm{l})$. The matched groups had 355 patients each with PGS $\leq 2.4 \mathrm{mmol} / \mathrm{l}$ (Group $1 \mathrm{M}$ ) and PGS $>2.4 \mathrm{mmol} / \mathrm{l}$ (Group 2M). The median PGS for Group1M was $1.3 \mathrm{mmol} / \mathrm{l}$ and Group 2M was $3.9 \mathrm{mmol} / \mathrm{l}$. The baseline characteristics of the whole and the matched cohort are presented in Table 1.

\section{Outcomes}

During a median follow up of 3.4 years, MACE was higher in Group 2 compared to Group 1, both in the unmatched and matched groups (Table 1). Event free survival was lower in group 2 and $2 \mathrm{M}$ than in group 1 and $1 \mathrm{M}$ respectively (Fig 1). Group 2 (HR 1.75, 95\% Cl 1.26 to $2.42, \mathrm{p}<0.001)$ and $2 \mathrm{M}(\mathrm{HR} 1.70,95 \% \mathrm{Cl} 1.21$ to $2.41, \mathrm{p}=0.003)$ independently predicted MACE. PGS, as a continuous variable was a predictor of MACE free survival when adjusted for several covariates for the unmatched and matched groups (Table 2). With every $\mathrm{mmol} / \mathrm{l}$ increase in PGS, there would be a $16 \%$ and $12 \%$ increase in the probability of MACE (Table 2).

The c-statistic of the base model increased from $0.744(95 \% \mathrm{Cl} 0.713$ to 0.773$)$ to 0.757 $(95 \% \mathrm{Cl} 0.727$ to 0.786$)$ on addition of PGS, $\delta A \cup C 0.013, p=0.046$ but not on addition of FPG $0.747,(95 \%$ Cl 0.716 to 0.776$)$, $\delta A U C ~ 0.003, p=0.143$ or 2 h-PG 0.752 (95\% Cl 0.722 to 0.781 ), $\delta A \cup C=0.008, p=0.146$. The $c$-statistics was higher when PGS was added to the base model compared to when $2 \mathrm{~h}-\mathrm{PG}$ was added, $\delta A \cup C 0.005, \mathrm{p}=0.034$. Addition of PGS to models containing only GRS or GRS and FPG, in association with other co-variates improved their predictive performance as measured by NRI>0 and IDI (Table 3 ). Within the whole cohort, PGS improved net reclassification by $28 \%$ when added to the model containing GRS only. Addition of PGS to the model containing GRS and FPG resulted in net reclassification improvement of $25.5 \%$. Discrimination improved in a similar pattern. These improvements were not seen with addition of FPG. There was a greater improvement in the predictive performance of the base model when PGS was added to it compared to when $2 \mathrm{~h}-\mathrm{PG}$ was added (NRI>0 0.2107, $\mathrm{p}=0.013$, IDI 0.0042, $\mathrm{p}=0.046)$. This suggests that PGS is a more powerful indicator of post-MI prognosis that $2 \mathrm{~h}-\mathrm{PG}$ itself.

\section{Discussion}


Several studies report worse post-MI prognosis in patients with newly diagnosed DM and

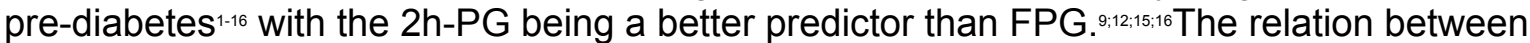
post-challenge glucose spike and post-MI prognosis in patients without known or newly diagnosed DM had not been studied. This is the first study to suggest that post-load blood glucose spike is an independent determinant and a better predictor of post-MI prognosis in these patients.

The effect of post-glucose spike defined as the difference between the fasting and 2 hour post-challenge glucose levels on prognosis in non-diabetic population was suggested in the DECODE study..$^{17}$ The largest number of excess deaths occurred in individuals with FPG $\leq 6.1 \mathrm{mmol} / \mathrm{l}$ and high glucose spike in terms of increase from baseline to $2-\mathrm{h}$ glucose value. The number of deaths in patients without newlydiagnosed DM increased as the difference between the fasting and $2 \mathrm{~h}-\mathrm{PG}$ increased. This is the first study to suggest this in a post-MI population. In the Diabetes Control and Complications Trial diabetic patients with similar $\mathrm{HbA} 1 \mathrm{c}$ treated conventionally had a higher risk of complications than those treated intensively. ${ }^{39}$ Although extent of postprandial glycaemic excursions was speculated as a possible cause, subsequent reanalysis explained the results by the differences in mean $\mathrm{HbA} 1 \mathrm{c}$ between treatment groups over time..$^{40}$ In our patients PGS as a continuous variable was a stronger predictor of prognosis than $2 \mathrm{~h}-\mathrm{PG}$ itself.

The effect of post-MI stress on glycaemic status makes the timing of OGTT relevant. Glucometabolic abnormalities are overestimated when measured within the first 24

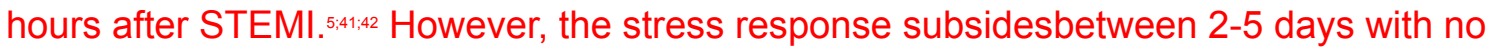
further decrease thereafter. ${ }^{43}$ OGTT results are more reproducible in patients with subendocardial rather than transmural infarctions. ${ }^{44}$ OGTT in this study was done $\geq 3$ days after admission and $55 \%$ of our patients had NSTEMI. Thus the glucose measurements are likely to be reproducible. More importantly, as PGS is the difference between $2 \mathrm{~h}-\mathrm{PG}$ and FPG, both of which are increased by stress, PGS unlikely to have been overestimated. This may be an advantage of measuring PGS rather than $2 \mathrm{~h}-\mathrm{PG}$ to mitigate the effect of stress on the glycaemic matrices.

Glycaemic variability (GV) has variably been implicated in adverse post-MI outcomes. MAGE during the first 72 hours of admission predicted MACE in anelderly ACS population $54 \%$ of whom had DM. ${ }^{28}$ In STEMI patients with and without DM undergoing primary PCI, MAGE was associated with short term MACE. $29: 30$ in another study, MAGE predicted post-ACS events only by marginal significance driven solely by its effect on events in patients with DM and did not improve the predictive performance of models not containing MAGE. ${ }^{31}$ In a large cohort of STEMI and NSTEMI patients, $38 \%$ of whom had DM, none of the GV matrices during first 48 hours of hospital admission was associated with overall adjusted in-hospital mortality. GV was associated with mortality in STEMI but not NSTEMI patients. ${ }^{32}$ In the Diabetic Patients With Acute Myocardial Infarction study, prognsis did not relate to GV in DM patients with AMI treated with insulin infusion. ${ }^{33}$ In patients with DM, GV did not predict post-MI mortality. ${ }^{34}$

GV is not identical to PGS. GV refers to fluctuation in glucose levels, typically characterized by hyperglycaemic spikes or 'excursions' following meals and quantified, as the standard deviation of plasma glucose levels, the interquartile range, or the mean amplitude of glycaemic excursion (MAGE). Measuring GV is cumbersome; requiring specialised equipment for continuous glucose monitoring (CGM) or frequent needle pricks for self monitoring of blood glucose (SMBG). This may be justified in the patients with DM where therapy tailored to the daily variations in blood glucose is required. This is not an appropriate test in patients without DM to assess their post-MI prognosis. MAGE only yield data about relative variability in blood glucose and not the absolute magnitude of glycaemic spikes. Our data suggests that in patients with known or newly diagnosed DM, the amplitude of a single 
post-load glucose spike is sufficient to predict post-MI prognosis negating the need for GV measurements.

PGS, defined as the difference between the 2 hour post-load and fasting glucose level during OGTT, adversely affects atherosclerosis. PGS, but not FPG or $\mathrm{HbA1c}$, is positively associated with carotid intima-media thickness, after adjustment for other co-variates, both in patients without ${ }^{19-22}$ and with DM. ${ }^{45}$ Progression of coronary atherosclerosis in non-diabetic, non-glucose-intolerant patients with coronary artery disease is associated with 2-hour post challenge glucose peak but not fasting glucose..$^{18}$ Glucose spikes can accelerate atherosclerotic lesion formation in non-diabetic mice model exposed to repetitive glucose infusion. ${ }^{46 ; 47} \mathrm{High} \mathrm{GV}$, after ACS, has been associated with progression of coronary plaque and plaque vulnerability. ${ }^{23-27}$ PGS is likely to affect the post-MI prognosis via these pathophysiological mechanisms.

Limitation

The study is limited by its retrospective observational design. This has been partially mitigated by comparing matched groups. Although every effort was made to ensure completeness of the data from hospital and general practice databases informationrecorded incompletely could not be used. Exclusion of a small number of patientsthat could not have the OGTT and mainly Caucasian study population could affect the generalizability of the results. All patients with known or newly diagnosed DM were excluded. Even without the use of admission $\mathrm{HbA} 1 \mathrm{c}$, undiagnosed DM is unlikely to have been missed using OGTT. Thus it is certain that the study cohort does not inadvertently include DM patients. Indicators of metabolic syndrome e.g. anthropometric measurements, assessment of insulin resistance etc. were not available and could have changed during the follow-up. OGTT was not repeated post-discharge. There is a possibility that patients may have crossed over between the two compared groups. However, the KM curves remain uniformly separated throughout follow up suggesting that the hazard assumption for the Cox analysis was proportional and therefore this is unlikely to have affected the results. As pre-DM is associated frequently with metabolic syndrome, in the absence of anthropometric measurements and other risk factors, it is unclear whether this affected outcomes.

\section{Conclusion}

In patients without known or newly diagnosed DM, post-load glucose spike is a determinant of post-MI. The post-load glucose spike is a stronger determinant of prognosis than 2-hour post-load glucose. This has important clinical implications. Firstly, to adequately prognosticate post-MI patients without diabetes, FPG alone is inadequate and $2 \mathrm{~h}-\mathrm{PG}$ is needed. Secondly, a single post-load glucose spike may obviate the need for cumbersome measurement of glycaemic variability that is very difficult to justify in non-diabetic patients. Thirdly, lifestyle interventions may have to be implemented in patients with high PGS even with normal glucose tolerance to prevent the development of diabetes. And finally, trials of SGLT2 inhibitors and GLP-1 receptor agonist may be needed to assess where blunting the PGS would improve post-MI prognosis.

\section{Acknowledgements}

The authors thank all the nurses that helped with the collection of data. They also thank the patients whose data were utilised for this study.

\section{Disclosures}

The author(s) declared no potential conflicts of interest with respect to the research, authorship, and/or publication of this article.

Funding

The author(s) received no financial support for the research, authorship, and/or publication of this article. 
Reference List

1. Kitada S, Otsuka Y, Kokubu N, Kasahara Y, Kataoka Y, Noguchi T et al. Post-load hyperglycemia as an important predictor of long-term adverse cardiac events after acute myocardial infarction: a scientific study. Cardiovasc Diabetol. 2010; 9: 75.

2. Tamita K, Katayama M, Takagi T, Akasaka T, Yamamuro A, Kaji S et al. Impact of newly diagnosed abnormal glucose tolerance on long-term prognosis in patients with acute myocardial infarction. Circ J. 2007; 71: 834841.

3. Bartnik M, Malmberg K, Norhammar A, Tenerz A, Ohrvik J, Ryden L. Newly detected abnormal glucose tolerance: an important predictor of long-term outcome after myocardial infarction. Eur Heart J. 2004; 25: 19901997.

4. Lenzen M, Ryden L, Ohrvik J, Bartnik M, Malmberg K, Scholte Op RW et al.

Diabetes known or newly detected, but not impaired glucose regulation, has a negative influence on 1-year outcome in patients with coronary artery disease: a report from the Euro Heart Survey on diabetes and the heart. Eur Heart J. 2006; 27: 29692974.

5. Knudsen EC, Seljeflot I, Abdelnoor M, Eritsland J, Mangschau A, Muller C et al. Impact of newly diagnosed abnormal glucose regulation on long-term prognosis in low risk patients with ST-elevation myocardial infarction: A follow-up study. BMC Endocr Disord. 2011; 11: 14.

6. Tenerz A, Nilsson G, Forberg R, Ohrvik J, Malmberg K, Berne C et al. Basal glucometabolic status has an impact on long-term prognosis following an acute myocardial infarction in non-diabetic patients. $J$ Intern Med. 2003; 254: 494503. 
7. Timmer JR, Hoekstra M, Nijsten MW, van $\mathrm{dH}$, I, Ottervanger JP, Slingerland RJ et al. Prognostic value of admission glycosylated hemoglobin and glucose in nondiabetic patients with ST-segment-elevation myocardial infarction treated with percutaneous coronary intervention. Circulation. 2011; 124: 704711.

8. Tamita K, Katayama M, Takagi T, Yamamuro A, Kaji S, Yoshikawa J et al. Newly diagnosed glucose intolerance and prognosis after acute myocardial infarction: comparison of post-challenge versus fasting glucose concentrations. Heart. 2012; 98: 848854.

9. George A, Bhatia RT, Buchanan GL, Whiteside A, Moisey RS, Beer SF et al. Impaired Glucose Tolerance or Newly Diagnosed Diabetes Mellitus Diagnosed during Admission Adversely Affects Prognosis after Myocardial Infarction: An Observational Study. PLoS One. 2015; 10: e0142045.

10. Pararajasingam G, Hofsten DE, Logstrup BB, Egstrup M, Henriksen FL, Hangaard $\mathrm{J}$ et al. Newly detected abnormal glucose regulation and long-term prognosis after acute myocardial infarction: Comparison of an oral glucose tolerance test and glycosylated haemoglobin A1c. Int J Cardiol. 2016; 214: 310315.

11. Aggarwal B, Shah GK, Randhawa M, Ellis SG, Lincoff AM, Menon V. Utility of Glycated Hemoglobin for Assessment of Glucose Metabolism in Patients With ST-Segment Elevation Myocardial Infarction. Am J Cardiol. 2016; 117: 749753.

12. Chattopadhyay S, George A, John J, Sathyapalan T. Two-hour post-challenge glucose is a better predictor of adverse outcome after myocardial infarction than fasting or admission glucose in patients without diabetes. Acta Diabetol. 2018; 55: 449458.

13. Gustafsson I, Kistorp CN, James MK, Faber JO, Dickstein K, Hildebrandt PR. Unrecognized glycometabolic disturbance as measured by hemoglobin A1c is associated with a poor outcome after acute myocardial infarction. Am Heart $\mathrm{J}$. 2007; 154: 470476.

14. Ritsinger V, Tanoglidi E, Malmberg K, Nasman P, Ryden L, Tenerz A et al. Sustained prognostic implications of newly detected glucose abnormalities in patients with acute myocardial infarction: long-term follow-up of the Glucose Tolerance in Patients with Acute Myocardial Infarction cohort. Diab Vasc Dis Res. 2015; 12: 2332.

15. Chattopadhyay S, George A, John J, Sathyapalan T. Adjustment of the GRACE score by 2-hour post-load glucose improves prediction of long-term major adverse cardiac events in acute coronary syndrome in patients without known diabetes. Eur Heart J. 2018; 39: 27402745.

16. Chattopadhyay S, George A, John J, Sathyapalan T. Pre-diabetes mellitus newly diagnosed after myocardial infarction adversely affects prognosis in patients without known diabetes. Diab Vasc Dis Res. 2019; 16: 489497. 
17. DECODE Study Group. Glucose tolerance and mortality: comparison of WHO and American Diabetes Association diagnostic criteria. The DECODE study group. European Diabetes Epidemiology Group. Diabetes Epidemiology: Collaborative analysis Of Diagnostic criteria in Europe. Lancet. 1999; 354: 617621.

18. Mellen PB, Bittner V, Herrington DM. Post-challenge glucose predicts coronary atherosclerotic progression in non-diabetic, post-menopausal women. Diabet Med. 2007; 24: 11561159.

19. Hanefeld M, Koehler C, Henkel E, Fuecker K, Schaper F, Temelkova-Kurktschiev T. Post-challenge hyperglycaemia relates more strongly than fasting hyperglycaemia with carotid intima-media thickness: the RIAD Study. Risk Factors in Impaired Glucose Tolerance for Atherosclerosis and Diabetes. Diabet Med. 2000; 17: 835840.

20. Temelkova-Kurktschiev TS, Koehler C, Henkel E, Leonhardt W, Fuecker K, Hanefeld M. Postchallenge plasma glucose and glycemic spikes are more strongly associated with atherosclerosis than fasting glucose or $\mathrm{HbA} 1 \mathrm{C}$ level. Diabetes Care. 2000; 23: 18301834.

21. Hanefeld M, Koehler C, Schaper F, Fuecker K, Henkel E, Temelkova-Kurktschiev T. Postprandial plasma glucose is an independent risk factor for increased carotid intima-media thickness in non-diabetic individuals. Atherosclerosis. 1999; 144: 229235.

22. Temelkova-Kurktschiev T, Koehler C, Schaper F, Henkel E, Hahnefeld A, Fuecker $\mathrm{K}$ et al. Relationship between fasting plasma glucose, atherosclerosis risk factors and carotid intima media thickness in non-diabetic individuals. Diabetologia. 1998; 41: 706712.

23. Gohbara M, Hibi K, Mitsuhashi T, Maejima N, Iwahashi N, Kataoka S et al. Glycemic Variability on Continuous Glucose Monitoring System Correlates With Non-Culprit Vessel Coronary Plaque Vulnerability in Patients With First-Episode Acute Coronary Syndrome - Optical Coherence Tomography Study. Circ J. 2016; 80: 202210.

24. Gohbara M, Iwahashi N, Kataoka S, Hayakawa Y, Sakamaki K, Akiyama E et al. Glycemic Variability Determined by Continuous Glucose Monitoring System Predicts Left Ventricular Remodeling in Patients With a First ST-Segment Elevation Myocardial Infarction. Circ J. 2015; 79: 10921099.

25. Kataoka S, Gohbara M, Iwahashi N, Sakamaki K, Nakachi T, Akiyama E et al. Glycemic Variability on Continuous Glucose Monitoring System Predicts Rapid Progression of Non-Culprit Lesions in Patients With Acute Coronary Syndrome. Circ J. 2015; 79: 22462254.

26. Okada K, Hibi K, Gohbara M, Kataoka S, Takano K, Akiyama E et al. Association between blood glucose variability and coronary plaque instability in patients with acute coronary syndromes. Cardiovasc Diabetol. 2015; 20: 111. 
27. Kuroda M, Shinke T, Sakaguchi K, Otake H, Takaya T, Hirota Y et al. Effect of daily glucose fluctuation on coronary plaque vulnerability in patients pre-treated with lipid-lowering therapy: a prospective observational study. JACC Cardiovasc Interv. 2015; 8: 800811.

28. Su G, Mi SH, Li Z, Tao H, Yang HX, Zheng H. Prognostic value of early in-hospital glycemic excursion in elderly patients with acute myocardial infarction. Cardiovasc Diabetol. 2013; 12: 33.

29. Zhang JW, He LJ, Cao SJ, Yang Q, Yang SW, Zhou YJ. Effect of glycemic variability on short term prognosis in acute myocardial infarction subjects undergoing primary percutaneous coronary interventions. Diabetol Metab Syndr. 2014; 6: 76.

30. Mi SH, Su G, Yang HX, Zhou Y, Tian L, Zhang T et al. Comparison of in-hospital glycemic variability and admission blood glucose in predicting short-term outcomes in non-diabetes patients with ST elevation myocardial infarction underwent percutaneous coronary intervention. Diabetol Metab Syndr. 2017; 9: 20.

31. Takahashi H, Iwahashi N, Kirigaya J, Kataoka S, Minamimoto Y, Gohbara M et al. Glycemic variability determined with a continuous glucose monitoring system can predict prognosis after acute coronary syndrome. Cardiovasc Diabetol. 2018; 17: 1160761.

32. Lipska KJ, Venkitachalam L, Gosch K, Kovatchev B, Van den BG, Meyfroidt G et al. Glucose variability and mortality in patients hospitalized with acute myocardial infarction. Circ Cardiovasc Qual Outcomes. 2012; 5: 550557.

33. Mellbin LG, Malmberg K, Ryden L, Wedel H, Vestberg D, Lind M. The relationship between glycaemic variability and cardiovascular complications in patients with acute myocardial infarction and type 2 diabetes: a report from the DIGAMI 2 trial. Eur Heart J. 2013; 34: 374379.

34. Monteiro S, Goncalves F, Monteiro P, Freitas M, Providencia LA. The magnitude of the variation in glycemia: a new parameter for risk assessment in acute coronary syndrome? Rev Esp Cardiol. 2009; 62: 10991108.

35. Thygesen K, Alpert JS, White HD. Universal definition of myocardial infarction. Eur Heart J. 2007; 28: 25252538.

36. Ryden L, Standl E, Bartnik M, Van den BG, Betteridge J, de Boer MJ et al. Guidelines on diabetes, pre-diabetes, and cardiovascular diseases: executive summary. The Task Force on Diabetes and Cardiovascular Diseases of the European Society of Cardiology (ESC) and of the European Association for the Study of Diabetes (EASD). Eur Heart J. 2007; 28: 88136.

37. Report of the Expert Committee on the Diagnosis and Classification of Diabetes Mellitus. Diabetes Care. 1997; 20: 11831197. 
38. Genuth S, Alberti KG, Bennett P, Buse J, Defronzo R, Kahn R et al. Follow-up report on the diagnosis of diabetes mellitus. Diabetes Care. 2003; 26: 31603167.

39. The relationship of glycemic exposure ( $\mathrm{HbA} 1 \mathrm{c})$ to the risk of development and progression of retinopathy in the diabetes control and complications trial. Diabetes. 1995; 44: 968983.

40. Lachin JM, Genuth S, Nathan DM, Zinman B, Rutledge BN. Effect of glycemic exposure on the risk of microvascular complications in the diabetes control and complications trial--revisited. Diabetes. 2008; 57: 9951001.

41. Knudsen EC, Seljeflot I, Abdelnoor M, Eritsland J, Mangschau A, Arnesen H et al. Abnormal glucose regulation in patients with acute ST- elevation myocardial infarction-a cohort study on 224 patients. Cardiovasc Diabetol. 2009; 8: 6.

42. Mazurek M, Kowalczyk J, Lenarczyk R, Zielinska T, Sedkowska A, Pruszkowska-Skrzep $P$ et al. The prognostic value of different glucose abnormalities in patients with acute myocardial infarction treated invasively. Cardiovasc Diabetol. 2012; 11: 78.

43. Tenerz A, Norhammar A, Silveira A, Hamsten A, Nilsson G, Ryden L et al. Diabetes, insulin resistance, and the metabolic syndrome in patients with acute myocardial infarction without previously known diabetes. Diabetes Care. 2003; 26: 27702776.

44. Hage C, Malmberg K, Ryden L, Wallander M. The impact of infarct type on the reliability of early oral glucose tolerance testing in patients with myocardial infarction. Int J Cardiol. 2010; 145: 259260.

45. Hu Y, Liu W, Huang R, Zhang X. Postchallenge plasma glucose excursions, carotid intima-media thickness, and risk factors for atherosclerosis in Chinese population with type 2 diabetes. Atherosclerosis. 2010; 210: 302306.

46. Shuto Y, Asai A, Nagao M, Sugihara H, Oikawa S. Repetitive Glucose Spikes Accelerate Atherosclerotic Lesion Formation in C57BL/6 Mice. PLoS One. 2015; 10: e0136840.

47. Mita T, Otsuka A, Azuma K, Uchida T, Ogihara T, Fujitani Y et al. Swings in blood glucose levels accelerate atherogenesis in apolipoprotein E-deficient mice. Biochem Biophys Res Commun. 2007; 358: 679685. 
Figure Legend

Figure 1. Kaplan-Meier curves showing survival free of MACE in the unmatched $(A)$ and matched (B) Groups divided by the median post-load glucose spike in each cohort. Group 1 $\leq$ median, Group $2>$ median.

Table 1. Baseline characteristics of patients.

\begin{tabular}{|l|c|c|c|c|c|c|}
\hline & $\begin{array}{c}\text { Group 1 } \\
\text { PGS } \leq 2.4 \\
\mathrm{n}=430\end{array}$ & $\begin{array}{c}\text { Group 2 } \\
\text { PGS>2.4 } \\
\mathrm{n}=417\end{array}$ & $\mathrm{p}$ & $\begin{array}{c}\text { Group 1M } \\
\text { PGS } \leq 2.4 \\
\mathrm{n}=355\end{array}$ & $\begin{array}{c}\text { Group 2M } \\
\text { PGS>2.4 } \\
\mathrm{n}=355\end{array}$ & $\mathrm{p}$ \\
\hline Male $\mathrm{n}(\%)$ & $294(68.4)$ & $311(74.6)$ & 0.046 & $237(66.8)$ & $269(75.8)$ & 0.008 \\
\hline Current smoker $\mathrm{n}(\%)$ & $166(38.6)$ & $134(32.1)$ & 0.049 & $126(35.5)$ & $121(34.1)$ & 0.693 \\
\hline Hypertension $\mathrm{n}(\%)$ & $141(32.8)$ & $171(41.0)$ & 0.013 & $127(35.8)$ & $133(37.5)$ & 0.640 \\
\hline Hypercholesterolaemia $\mathrm{n}(\%)$ & $87(20.2)$ & $101(24.2)$ & 0.163 & $71(20.0)$ & $82(23.1)$ & 0.315 \\
\hline Previous AMI $\mathrm{n}(\%)$ & $58(13.5)$ & $86(20.6)$ & 0.006 & $52(14.7)$ & $52(14.7)$ & 1.000 \\
\hline $\begin{array}{l}\text { Previous revascularisation } \mathrm{n} \\
\text { (\%) }\end{array}$ & $29(6.7)$ & $41(9.8)$ & 0.103 & $23(6.5)$ & $25(7.0)$ & 0.765 \\
\hline Previous PVD n (\%) & $16(3.7)$ & $14(3.4)$ & 0.775 & $11(3.1)$ & $12(3.4)$ & 0.832 \\
\hline Previous CVA n (\%) & $13(3.0)$ & $20(4.8)$ & 0.183 & $9(2.5)$ & $13(3.7)$ & 0.386 \\
\hline Normal LVEF & $364(84.6)$ & $341(81.8)$ & 0.262 & $299(84.2)$ & $295(83.1)$ & 0.685 \\
\hline Diagnosis NSTEMI $\mathrm{n}(\%)$ & $249(57.9)$ & $218(52.3)$ & 0.099 & $205(57.7)$ & $185(52.1)$ & 0.131 \\
\hline Discharge Medications & & & & & & \\
\hline
\end{tabular}




\begin{tabular}{|c|c|c|c|c|c|c|}
\hline Aspirin n (\%) & $418(97.2)$ & $393(94.2)$ & 0.033 & $345(97.2)$ & $338(95.2)$ & 0.169 \\
\hline Clopidogrel n (\%) & $396(92.1)$ & $367(88.0)$ & 0.047 & $283(79.7)$ & $284(80.0)$ & 0.925 \\
\hline Beta-blocker n (\%) & $310(72.1)$ & $311(74.5)$ & 0.413 & $254(71.6)$ & $270(76.1)$ & 0.172 \\
\hline ACEI/ARB n (\%) & $332(77.2)$ & $335(80.3)$ & 0.266 & $274(77.2)$ & $288(81.1)$ & 0.196 \\
\hline Statin n (\%) & $373(86.7)$ & $357(85.6)$ & 0.633 & $309(87.0)$ & $304(85.6)$ & 0.585 \\
\hline \multicolumn{7}{|l|}{ GRACE variables } \\
\hline Age years (median, IQR) & 60.4(18.5 & $\begin{array}{c}66.9(17.4 \\
)\end{array}$ & $\begin{array}{c}<0.00 \\
1\end{array}$ & $62.0(18.7)$ & 64.7(16.3 & 0.070 \\
\hline Heart rate bpm (median, IQR) & $75(25)$ & $74(26)$ & 0.707 & $76(25)$ & $74(25)$ & 0.427 \\
\hline SBP mmHg (median, IQR) & 139(32) & 138(39) & 0.506 & 139(32.0) & $138(38.0)$ & 0.477 \\
\hline $\begin{array}{l}\text { Creatinine } \mu \mathrm{mol} / \mathrm{I} \\
\text { (median, IQR) }\end{array}$ & 94(22) & $99(24.5)$ & $\begin{array}{c}<0.00 \\
1\end{array}$ & $93(21.8)$ & $98(21.0)$ & $\begin{array}{c}<0.00 \\
1\end{array}$ \\
\hline Heart failure $\mathrm{n}(\%)$ & $15(3.5)$ & $20(4.8)$ & 0.339 & $12(3.4)$ & $10(2.8)$ & 0.665 \\
\hline ST segment depression n (\%) & $295(68.6)$ & $307(73.6)$ & 0.108 & $245(69.0)$ & $266(74.9)$ & 0.079 \\
\hline Troponin rise $\mathrm{n}(\%)$ & 429(99.8) & 413(99.0) & 0.168 & 355(100.0 & 352(99.2) & 0.083 \\
\hline Cardiac Arrest n (\%) & $14(3.3)$ & $18(4.3)$ & 0.418 & $11(3.1)$ & $17(4.8)$ & 0.247 \\
\hline \multicolumn{7}{|l|}{ GRACE Score } \\
\hline $\begin{array}{l}\text { Admission-6m Death (median, } \\
\text { IQR) }\end{array}$ & $105(39.0)$ & 116(39.0) & $\begin{array}{c}<0.00 \\
1\end{array}$ & 109(39.3) & $113(35.7)$ & 0.196 \\
\hline $\begin{array}{l}\text { Admission-6m Death/MI } \\
\text { (median, IQR) }\end{array}$ & $157(47.0)$ & $167(50.0)$ & $\begin{array}{c}<0.00 \\
1\end{array}$ & $157(44.5)$ & $164(28.0)$ & 0.148 \\
\hline $\begin{array}{l}\text { Discharge-6m Death (median, } \\
\text { IQR) }\end{array}$ & $108(41.0)$ & 119(38.0) & $\begin{array}{c}<0.00 \\
1\end{array}$ & $112(40.0)$ & 116(35.0) & 0.0138 \\
\hline $\begin{array}{l}\text { Discharge-6m Death/MI } \\
\text { (median, IQR) }\end{array}$ & $113(37.0)$ & 123(48.0) & $\begin{array}{c}<0.00 \\
1\end{array}$ & $113(37.0)$ & $113(37.0)$ & 0.250 \\
\hline \multicolumn{7}{|l|}{ Glucose levels } \\
\hline FPG (mmol/I) (median, IQR) & $4.9(0.6)$ & $5.0(0.7)$ & 0.003 & $4.9(0.6)$ & $5.0(0.7)$ & 0.122 \\
\hline 2h-PG (mmol/l) (median, IQR) & $6.25(1.5)$ & $9.0(2.0)$ & $\begin{array}{c}<0.00 \\
1\end{array}$ & $6.3(1.4)$ & $8.9(2.0)$ & $\begin{array}{c}<0.00 \\
1\end{array}$ \\
\hline $\begin{array}{l}\text { Post load glucose spike } \\
(\mathrm{mmol} / \mathrm{l})\end{array}$ & $1.3(1.2)$ & $3.9(1.9)$ & $\begin{array}{c}<0.00 \\
1\end{array}$ & $1.3(1.1)$ & $3.9(1.9)$ & $\begin{array}{c}<0.00 \\
1\end{array}$ \\
\hline NGT $n(\%)$ & 408(94.9) & $61(14.6)$ & $\begin{array}{c}<0.00 \\
1\end{array}$ & $337(94.9)$ & $51(14.4)$ & $\begin{array}{c}<0.00 \\
1\end{array}$ \\
\hline MACE n (\%) & $61(14.2)$ & 114(27.3) & $\begin{array}{c}<0.00 \\
1\end{array}$ & $55(15.5)$ & $87(24.5)$ & 0.003 \\
\hline Deaths n (\%) & 25( & $60(1$ & $\begin{array}{c}<0.00 \\
1\end{array}$ & $32(9.0)$ & $44(12.4)$ & 0.145 \\
\hline Re-infarctions $\mathrm{n}(\%)$ & $36(8.4)$ & $54(12.9)$ & 0.031 & $23(6.5)$ & $43(12.1)$ & 0.010 \\
\hline
\end{tabular}

AMI, Acute myocardial infarction; PVD, peripheral vascular disease; CVA, cerebrovascular accident; LVEF, left ventricular ejection fraction; NSTEMI' non-ST elevation myocardial infarction; ACEI/ARB, angiotensin-converting enzyme inhibitor/angiotensin receptor blocker; GRACE, Global Registry of Acute Coronary Events; IQR, interquartile range; HR, heart rate; SBP, systolic blood pressure; FPG, fasting plasma glucose; 2HBG, 2 hour plasma glucose; NGT, normal glucose tolerance; MACE, major adverse cardiovascular events.

Table 2.. Predictors of major adverse cardiovascular events.

\begin{tabular}{|l|c|c|c|c|c|c|}
\hline & \multicolumn{3}{|c|}{ Whole Cohort } & \multicolumn{3}{|c|}{ Matched Cohort } \\
\hline Covariate & $\mathrm{HR}$ & $95 \% \mathrm{Cl}$ & $\mathrm{P}$ & $\mathrm{HR}$ & $95 \% \mathrm{Cl}$ & $\mathrm{P}$ \\
\hline Discharged without Aspirin & 1.77 & 1.02 to 3.06 & 0.043 & 1.56 & $\begin{array}{c}0.81 \text { to } \\
3.03\end{array}$ & 0.182 \\
\hline $\begin{array}{l}\text { Discharged without } \\
\text { clopidogrel }\end{array}$ & 1.58 & 1.03 to 2.42 & 0.035 & 1.98 & $\begin{array}{c}1.17 \text { to } \\
3.34\end{array}$ & 0.012 \\
\hline GRACE Score & 1.01 & 1.01 to 1.01 & $<0.001$ & 1.01 & $\begin{array}{c}1.01 \text { to } \\
1.02\end{array}$ & $<0.001$ \\
\hline Previous AMI & 1.95 & 1.29 to 2.94 & 0.001 & 1.88 & $\begin{array}{c}1.16 \text { to } \\
3.05\end{array}$ & 0.010 \\
\hline
\end{tabular}




\begin{tabular}{|l|c|c|c|c|c|c|}
\hline Hypercholesterolaemia & 0.67 & 0.45 to 0.99 & 0.043 & 0.66 & $\begin{array}{c}0.43 \text { to } \\
1.02\end{array}$ & 0.063 \\
\hline Post load glucose spike & 1.16 & 1.06 to 1.26 & 0.002 & 1.12 & $\begin{array}{c}1.02 \text { to } \\
1.24\end{array}$ & 0.021 \\
\hline
\end{tabular}

The full model included gender, smoking status, hypercholesterolaemia, hypertension, history of previous acute $\mathrm{Ml}$, diagnosis at discharge, discharge prescription of aspirin, clopidogrel, beta-blockers, angiotensin-converting enzyme inhibitors and statins, inpatient revascularization status and GRACE risk score, fasting plasma glucose. Abbreviations as in the text.

Table 3. Net reclassification index and integrated discrimination index for model improvement with the addition of PGS or FPG to the model with only GRACE score.

\begin{tabular}{|c|c|c|c|c|}
\hline & \multicolumn{4}{|c|}{ All patients } \\
\hline & EVENT & $\begin{array}{l}\text { NONEVEN } \\
T\end{array}$ & TOTAL & $\mathrm{p}$ \\
\hline \multicolumn{5}{|c|}{ GRS v GRS+FPG } \\
\hline UP & 93 & 331 & 424 & \\
\hline DOWN & 82 & 341 & 423 & \\
\hline$\overline{\text { TOTAL }}$ & 175 & 672 & 847 & \\
\hline$\overline{N R I}$ & 0.0628 & 0.0149 & 0.0777 & 0.3597 \\
\hline \multicolumn{5}{|c|}{ GRS v GRS+PGS } \\
\hline UP & 93 & 263 & 356 & \\
\hline DOWN & 82 & 409 & 491 & \\
\hline TOTAL & 175 & 672 & 847 & \\
\hline NRI & 0.0628 & 0.2173 & 0.2801 & $<0.000$ \\
\hline \multicolumn{5}{|c|}{ GRS+FPG $\vee G R S+F P G+P G S$} \\
\hline UP & 90 & 260 & 350 & \\
\hline DOWN & 85 & 412 & 497 & \\
\hline TOTAL & 175 & 672 & 847 & \\
\hline \multirow[t]{3}{*}{$\overline{\mathrm{NRI}}$} & 0.0286 & 0.2262 & 0.2548 & 0.0027 \\
\hline & & & & \\
\hline & IDle & IDIne & IDI & $p$ \\
\hline \multicolumn{5}{|c|}{ GRS v GRS+FPG } \\
\hline & 0.00022 & -0.00004 & 0.00026 & 0.8143 \\
\hline \multicolumn{5}{|c|}{ GRS v GRS+PGS } \\
\hline & 0.00736 & -0.00189 & 0.00925 & 0.0299 \\
\hline \multicolumn{5}{|c|}{ GRS+FPG $\vee$ GRS+FPG+PGS } \\
\hline & 0.00766 & -0.00197 & 0.00964 & 0.0260 \\
\hline & & & & \\
\hline
\end{tabular}

NRI, net reclassification index; UP, number of patients with and without event whose probability of MACE increased with adding a variable to the restricted model; DOWN, number of patients with and without event whose probability of MACE decreased with adding a variable to the restricted model; IDle, integrated discrimination index event; IDIne, integrated discrimination index non-event. 